\title{
The Role of Ultrasound in Intestinal Inflammatory Processes in Children and Adolescents
}

\author{
M. Epifanio ${ }^{1,2}$, Valéria Sgnaolin ${ }^{1}$, Matteo Baldisserotto ${ }^{2}$ \\ ${ }^{1}$ Universidade de Santa Cruz do Sul, Santa Cruz do Sul, Brazil \\ ${ }^{2}$ Pontifícia Universidade Católica do Rio Grande do Sul, Porto Alegre, Brazil \\ Email: mepifanio@hotmail.com
}

Received July 24, 2013; revised August 24, 2013; accepted August 31, 2013

Copyright (c) 2013 M. Epifanio et al. This is an open access article distributed under the Creative Commons Attribution License, which permits unrestricted use, distribution, and reproduction in any medium, provided the original work is properly cited. In accordance of the Creative Commons Attribution License all Copyrights (C) 2013 are reserved for SCIRP and the owner of the intellectual property M. Epifanio et al. All Copyright (c) 2013 are guarded by law and by SCIRP as a guardian.

\begin{abstract}
Purpose: To disseminate the current knowledge about the intestinal inflammatory processes in children and its approach by ultrasound (US) and provide necessary information to pediatricians for early diagnosis through this complementary method. Source of Data: The sources of data were selected by Medline, the international manuscripts, international medical journals more relevant in the last 20 years about Gray Scale and Color Doppler Ultrasound in the evaluation of inflammatory bowel disease in children and adolescents. Conclusions: Several authors have suggested that the ultrasound should be the first study in the diagnostic investigation process in suspected inflammatory bowel disease to determine the most affected region and monitor the therapy response. While colonoscopy still remains as the reference diagnostic method, the literature suggests that US can be an extremely useful tool in the context of the suspected diagnosis of a wide variety of intestinal inflammatory processes in children.
\end{abstract}

Keywords: Ultrasonography Doppler Color; Inflammatory Bowel Disease; Child

\section{Introduction}

Abdominal pain, diarrhea, bowel's bleeding and weight loss are very common symptoms in children and adolescents. These signs or symptoms, which could be indicating an intestinal inflammatory process, represent the majority of reasons for consultation with pediatric gastroenterologists. The intestinal inflammatory processes in children may present with these nonspecific symptoms or signs and characteristics of different diseases. Among children, the diagnosis of inflammatory bowel disease (IBD) is often missed or delayed because of the nonspecific nature of the intestinal and extra-intestinal symptoms at presentation which overlap functional bowel disorders. This requires the pediatrician to address a wide range of differential diagnoses and multiple diagnoses excluded by invasive studies, such as contrast radiological and endoscopic studies. Currently, however, it has several additional non-invasive tests which can help diagnosis. The aim of this review is to discuss the current knowledge about the intestinal inflammatory processes in children and its approach by ultrasound.

\section{Intestinal Inflammatory Processes}

The term intestinal inflammatory process covers a very heterogeneous group of diseases. These include, for example, IBD, allergic processes, vascular and infectious and polyps. The IBD is a chronic disease of unknown etiology that occurs with periods of remission and relapse, but is able to develop an inflammatory reaction in the lining of the digestive tract of immunological nature. Based on clinical, radiological, endoscopic and histological characteristics, is classified as: Crohn's disease (CD), ulcerative colitis (UC) and Indeterminate Colitis (IC). The inclusion of this third category is the fact that $10 \%$ to $15 \%$ of patients did not have specific macro and microscopically well defined [1,2].

In agreement with several epidemiological studies conducted in Western countries, it was demonstrated recently, an increase of 10 times the incidence of IBD in children in Italy, between 1979 and 2002 [3,4]. Even in the pediatric population with suspicion of IBD, it is initiated an investigation to establish the diagnosis early. The delay in diagnosis involves not only acute problems such 
as anemia and infections, but also irreversible adverse effects on growth and development of the child $[5,6]$.

The CD is an inflammatory disease that affects all segments of the digestive tract, so not continuously (alternating with normal mucosa compromised). The lesion may be located anywhere in the digestive tract from mouth to anus, reaching across the wall thickness (transmural). Onset may be insidious or abrupt, similar to a picture of acute abdomen, such as acute appendicitis. The slow start can occur with abdominal pain, diarrhea with malabsorption, the small is affected, or bloody diarrhea, if there is injury to the colon. Eventually, it can evolve only with fever; fall in the group of patients with fever of unknown origin $[7,8]$.

The intestinal neovascularization, which occurs mainly in DII in activity, is related to the increase in serum levels of fibroblast growth factor and with an intense stimulation of angiogeneses [9]. The increased vascularity was demonstrated, both histologically as angiographically, and by colonoscopy. Colonoscopies are indices of disease activity, which help in deciding the modality in the diagnosis and therapy of recidivas [10-12]. An endoscopy is an indispensable tool in the diagnosis of intestinal inflammatory processes, but is an invasive method, a cost high and requires general anesthesia [13].

New non-invasive serological tests, however, have emerged with the intent to facilitate the differential diagnosis, creating conditions for the establishment of the stage of disease, can follow its evolution and therapeutic response. Many noninvasive methods that can be used in monitoring of patients with IBD are laboratory tests, such as values of sedimentation globular, C-reactive protein, calciprotein and faecal alpha 1 antitrypsin between fecal and others [14].

According to the study of Ruess et al. [15], GS and color Doppler significant changes were noted in disease activity in patients with IBD who underwent treatment. Seventeen patients were studied, thirteen with $C D$ and four with UC. All had at least one intestinal segment abnormal, thickened and hyperemic. The wall was considered thickened when it was greater than $3 \mathrm{~mm}$, and hyperemic, according to the degree of Doppler: grade 1 (no blood), grade 2 (minimal vascularization or 1 to 5 pixels/ square inch), grade 3 (vascularization moderate or greater than 5 pixels/square $\mathrm{cm}$ ), grade 4 (large increase in vascularization, including vessels or discrete areas of vascular confluence). Ultrasound examinations were performed with the control in color Doppler, assessing such segments, which was gradual reduction of both the thickness of the bowel as the degree of vascularization Doppler, together with clinical improvement of patients [15].

Cow's milk allergy (CMA) manifests itself during the first months of life, producing an inflammatory intestinal important. The gastrointestinal manifestations include chronic diarrhea with malabsorption, gastroesophageal reflux, constipation, vomiting, poor weight gain, anemia and upper gastrointestinal bleeding and low imunity [16]. Such changes gastrointestinal disease states that may be suggested by radiological contrast studies and ultrasound sonografia [17]. In this case, patients may present antropyloric dyskinesia (pyloric spasm) with delayed gastric emptying. These can be highlighted, both by contrast radiography of the stomach and duodenum, as by scintigraphy. In some cases, ultrasound may also demonstrate antral mucosal thickening. The colitis is common in these patients and is demonstrated by colonoscopy. Patenaude [18] described the first case of CMA, whose diagnosis was suggested by US, 39 studied a patient for two months of life in exclusive breastfeeding, which was evaluated by presenting part of vomiting, stool with a history of blood and important history of irritability. Hypertrophic stenosis of pylorus, and infectious colitis aganglionosis were discarded. In ultrasound studies, a left spastic colon was found, with loss of differentiation of the layers of the intestinal wall and a marked thickening of the mucosa and submucosa. These findings were not seen again, after five days of treatment formula based on hydrolyzed protein, and diet of exclusion, with complete restoration of the normal US standard.

Inflammatory or juvenile polyps usually occur between four and ten years of age and can present as points of blood in the stool or sometimes with bleeding profusely, painless, and that usually does not cause hemodynamic serious disturbance. The juvenile polyps are usually single and bleeding can express their self-amputation.

Among other intestinal inflammatory processes, we can mention those of vascular origin, and the most common are: Henoch Schonlein Purpura of idiopathic and vasculitis. There are the infectious processes, among which you can highlight those related to diarrhea associated with Clostridium difficile and intestinal, among others.

\section{Gray Scale and Color Doppler Ultrasound}

The ultrasound (US) is one of the methods of diagnostic imaging more versatile and has the advantage of being noninvasive, less costly, and easily repeatable, and thus can be very useful in following up patients with IBD [19]. It is a very safe diagnostic procedure that uses high frequency sound waves to create images of internal structures of the body. The US equipment provides a bi dimensional view in a gray scale (GS) with the color and pulsate Doppler. The effect on color Doppler detects structures in motion, such as blood flow within a vessel. The color of Doppler represents the vessels of anatomical tissues and organs in different colors. The red color 
represents the flow towards the probe, blue represents the flow moving away the probe and yellow and white a high speed or turbulent flow. The pulsate Doppler is the flow inside the blood vessel through a graph.

In recent years, the US has been increasingly used in pediatric population, in the initial evaluation of gastrointestinal inflammatory processes, acute and chronic, such as appendicitis, inflammatory bowel disease, food allergy and polyposis, among others (Figures 1(a) and (b)) [2023]. In prospective controlled study with 62 neonates were evaluated for sensitivity and specificity of color Doppler, compared to simple abdominal radiology in the diagnosis of enterocolitis necrosante. It results showed a higher sensitivity and specificity of color Doppler ultrasound, suggesting that this study is part of the initial assessment of any neonate with clinical features sugges-

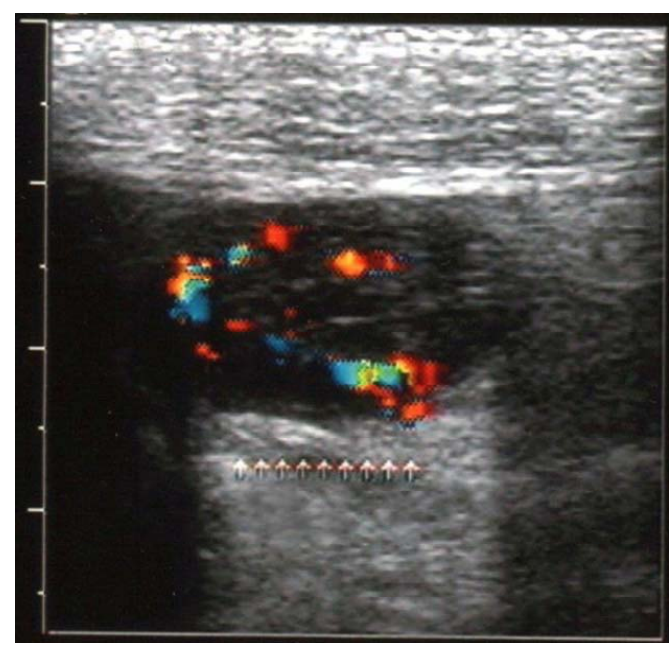

(a)

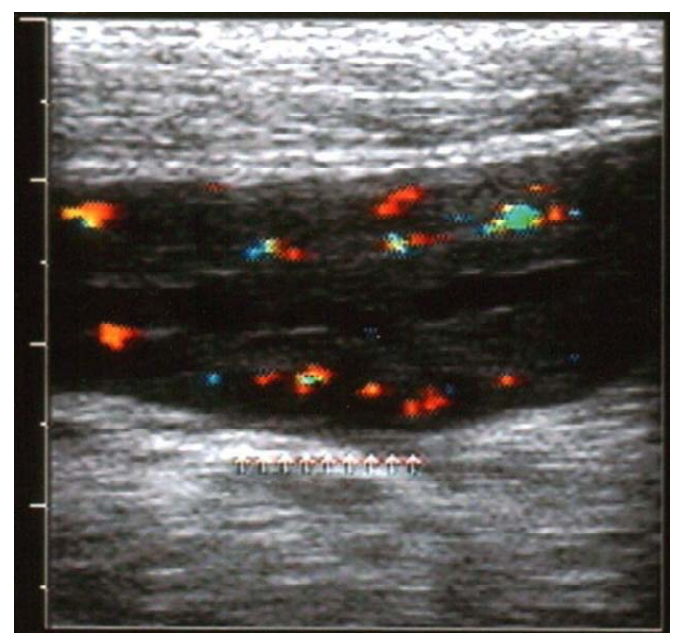

(b)

Figure 1. A 10 year-old boy presented abdominal pain, rectal bleeding and diarrhea. Longitudinal (a) and transverse (b) views of terminal ileum scanned with Color Doppler ultrasound showed increase vessels in the wall. (Figures of authors). tive of necrotizing enterocolitis. It was found that the absence of flow in the intestinal wall, suggesting ischemia, and increased vascularization of the same, indicating an inflammatory process incipient, are aspects that facilitate the clinical management early [24].

The value of color Doppler in the evaluation of children and adults with intestinal inflammatory processes is already well established, and the resource has already been used for some years [25-28]. The first studies in children were performed by Quillin and Siege [29,30] that noted that in the color Doppler can differentiate extrinsic causes of intestinal disease, such as peritonitis, to primary intestinal processes and identify different locations compromised. Several authors have suggested US as the first study to be conducted in the diagnostic investigation process of suspected inflammatory bowel disease [13,31-33].

Grey-scale sonography can evaluate the severity of wall thickening, the extent and distribution of colitis and transmural colitis, and the involvement of small bowel. In most studies, the bowel is considered to be thickened when the wall diameter exceeds $3 \mathrm{~mm}[19,34]$. In 1997, Siegel et al. [35] evaluated using GS and color Doppler 37 children with various intestinal inflammatory processes. They concluded that age, location of disease, the thickening of the intestinal wall and the flow are the most important predictors of type of disease, or ischemic, inflammatory or vascular. The thickness of the intestinal wall in patients with inflammatory diseases was $7.8 \mathrm{~mm}$ $\pm 2.7 \mathrm{~mm}$, in patients with vasculitis, $7.6 \mathrm{~mm} \pm 1.6$, and in patients with ischemia, $14.6 \pm 3.6 \mathrm{~mm}$, and the difference statistically significant. This study also evaluated the bowel wall flows and the wall echotexture and related those findings to the clinic diagnosis. The diagnostic performance of intestinal thickness in assessment of severe inflammatory processes is well established in the literature for other authors [36-39].

Spalinger et al. [40] evaluating patients with Crohn's disease, showed that the positive predictive value of US study in the determination of inflammatory processes, increases considerably when the thickness is assessed jointly and intestinal vasculature. Colour Doppler sonography can detect increases in bowel wall perfusion and show changes in disease activity in paediatric patients with bowel inflammation [15]. So called 'vessel density' on Doppler US has been shown to be an indicator with respect to disease activity and has been used to evaluate risk of relapse, but cannot provide information on the severity of disease [34,41].

The current literature shows excellent sensitivity of between $78 \%$ and $96 \%$ with specificity between $67 \%$ and $100 \%$ for US in IBD [42]. Limitations of this modality are operator dependence and difficulties to assess anatomical region by air-filled bowel or large body habitus 
$[43,44]$. Moreover, with the in color Doppler, it observed an increase in flow in the intestinal mucosa and transmural in patients with a wide variety of inflammatory bowel disease, but these ultrasound findings, are not specific to any type of disease, as any inflammatory process produces neovascularization. In the inflammatory process, Crohn's disease usually affects the terminal ileum and right colon, ulcerative retocolitis usually affects distal segments of colon (rectum and sigmoid) or the entire colon and pseudomembranous colitis the entire colon or the right colon. In the vasculitis process like allergic purpura usually affects the small bowel. Finally in the ischemic process, neutropenic typhlitis usually affects the right colon, and hemolytic uremic syndrome (ischemia) usually affects right colon or entire colon [34].

\section{Colonoscopy and Histopathology Study}

The colonoscopy examination in children is being used with increasing frequency in recent years. Accurate and safe, allows diagnosis of lesions under direct vision in the rectum, colon and ileum and collecting material for pathological examination also allows the treatment of various pathologies, in pediatric normal and present in these segments, such as the polypectomy. The success in evaluating the ileum by penetration through the ileocecal valve depends on the experience of the endoscopist. In adult patients, the ileum is seen in about $90 \%$ of examinations, but this percentage is lower in pediatric patients (Figure 2) [4].

The main indications for colonoscopy, in Pediatrics, are: lower gastrointestinal bleeding, chronic diarrhea with blood, perianal fistulas, and familial polyposis as shown in Table 1. The main complications of the colonoscopy study are bleeding and perforation, which occurs mainly in children and with intense mucosal inflammatory process. Risk factors for perforation include severe colitis and polypectomy. Other complications result from the preparation of the colon (dehydration, bac-

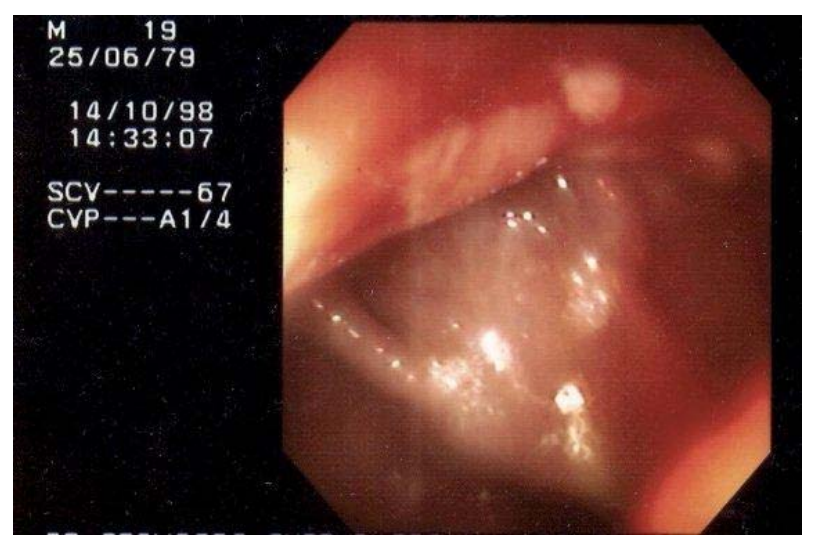

Figure 2. Terminal ileum imaging shows deep fissuring ulcers and friability.
Table 1. Main indications for performing colonoscopy in children.

\begin{tabular}{cc}
\hline Lower gastrointestinal bleeding & Diarrhea \\
\hline Juvenile polyps & Pseudomembranous colitis \\
& Infectious colitis \\
& Cytomegalovirus \\
Herpes \\
HIV \\
Crohn's disease & Clostridium difficile \\
& Tuberculosis \\
Ulcerative rectocolitis & Suspected Colorectal tumors \\
Nodular lymphoid hyperplasia & Chronic abdominal pain \\
Allergic colitis & Questions in the morbidity \\
Colorectal variceal & associated with barium enema \\
& Anemia without etiology \\
\hline
\end{tabular}

teremia) and anesthesia. Contraindications for colonoscopy are instabilities cardiovascular, respiratory or neurological, and coagulopathy suspected perforation, especially if it is necessary to perform biopsies or procedures.

Even with a normal colonoscopy examination, the biopsies are essential to assist in the diagnostic investigation and exclude microscopic changes. Biopsies of the ileum and colon have a key role in the establishment of the causes of chronic diarrhea, in distinction from various forms of colitis, in determining the extent of diseases and check the appearance of neoplasms in patients with chronic colitis and DII. The histological diagnosis of colitis is determined mainly from the evaluation of the architecture of the epithelium, the lamina propria cellularity, presence of polymorphonuclear neutrophils, or eosinophilic infiltrate and epithelial changes (Figure 3).

\section{Conclusion}

Several authors have suggested that US is the first study in the diagnostic process in suspected inflammatory bowel disease to determine the most affected region and monitor the therapy response. While colonoscopy still remains as the reference diagnostic method, the literature suggests that US can be an extremely useful tool in the context of the suspected diagnosis of a wide variety of intestinal inflammatory processes. The recent advances achieved with the new techniques have enabled the US to this method as a promising indication for the screening of these patients. This modality allows evaluating bowel segments, which are difficult to access by other methods, and perform diagnostics more often and early. The observation of an inflamed bowel segment in the GS and in color Doppler alerts the doctor about changes of the intestine, and increases the acceptance of parents as the indication of a more invasive, as colonoscopy. At the same time, if the ultrasound studies are normal, it is pos- 


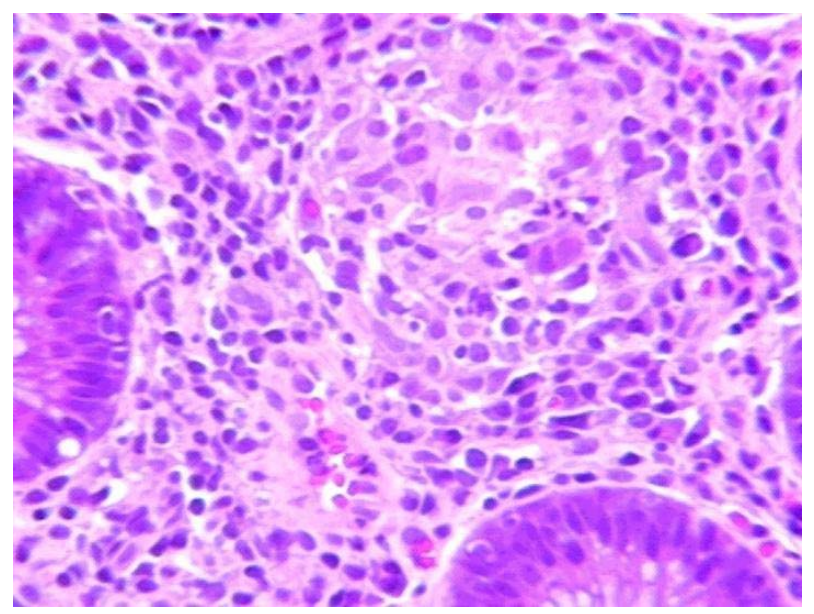

Figure 3. Histology view of a granuloma, confirming the diagnosis of Crohn's disease.

sible to monitor the clinical course and maintain an expectant conduct, for more invasive diagnostic methods. Furthermore, in a patient with known IBD and abdominal findings, US can be an alternative exam to monitor and follow disease.

\section{REFERENCES}

[1] M. Guindi and R. H. Riddell, "Indeterminate Colitis," Journal of Clinical Pathology, Vol. 57, No. 12, 2004, pp. 1233-1244. http://dx.doi.org/10.1136/jcp.2003.015214

[2] G. T. Martland and N. A. Shepherd, "Indeterminate Colitis: Definition, Diagnosis, Implications and a Plea for Nosological Sanity," Histopathology, Vol. 50, No. 1, 2007, pp. 83-96.

http://dx.doi.org/10.1111/j.1365-2559.2006.02545.x

[3] D. Knafelz, B. Papadatou, A. Barabino, R. B. Canani, S. Cucchiara, P. Lionetti, S. Martelossi and L. Zancan, "Epidemiology of Paediatric Inflammatory Bowel Disease in Italy: Results from the National Register,” Journal of Pediatric Gastroenterology \& Nutrition, Vol. 39, Suppl. 1, 2004, p. S282.

http://dx.doi.org/10.1097/00005176-200406001-00718

[4] IBD Working Group of the European Society for Paediatric Gastroenterology, Hepatology and Nutrition, "Inflammatory Bowel Disease in Children and Adolescents: Recommendations for Diagnosis-The Porto Criteria," Journal of Pediatric Gastroenterology \& Nutrition, Vol. 41, 2005, pp. 1-7.

[5] E. Hait, A. Bousvaros and R. Grand, "Pediatric Inflammatory Bowel Disease: What Children Can Teach Adults," Inflammatory Bowel Diseases, Vol. 11, No. 9, 2005, pp. 519-527. http://dx.doi.org/10.1097/01.MIB.0000166932.66853.fd

[6] A. Bousvaros, D. A. Antonioli, R. B. Colletti, M. C. Dubinsky, J. N. Glickman, B. D. Gold BD, et al., "North American Society for Pediatric Gastroenterology, Hepatology, and Nutrition; Colitis Foundation of America, "Differentiating Ulcerative Colitis from Crohn Disease in
Children and Young Adults: Report of a Working Group of the North American Society for Pediatric Gastroenterology, Hepatology, and Nutrition and the Crohn's and Colitis Foundation of America," Journal of Pediatric Gastroenterology and Nutrition, Vol. 44, 2007, pp. 653674.

[7] D. Barbieri, "Doenças Inflamatórias Intestinais,” Jornal de Pediatria, Vol. 76, Suppl. 1, 2000, pp. 173-180. http://dx.doi.org/10.2223/JPED.151

[8] J. S. Hyams and J. F. Markowitz, "Can We Alter the Natural History of Crohn Disease in Children?” Journal of Pediatric Gastroenterology and Nutrition, Vol. 40, No. 3, 2005, pp. 262-272.

http://dx.doi.org/10.1097/01.MPG.0000154660.62359.FE

[9] A. Bousvaros, D. Zurakowski, S. J. Fishman, K. Keough, T. Law, C. Sun, et al., "Serum Basic Fibroblast Growth Factor in Pediatric Crohn's Disease. Implications for Wound Healing,” Digestive Diseases and Sciences, Vol. 42, No. 2, 1997, pp. 378-386. http://dx.doi.org/10.1023/A:1018882322566

[10] M. Daperno, G. D’Haens, G. Van Assche, P. Bulois, V. Maunoury, R. Sostegni, et al., "Development and Validation of a New, Simplified Endoscopic Activity Score for Crohn's Disease: The SES-CD,” Gastrointestinal Endoscopy, Vol. 60, No. 4, 2004, pp. 505-512. http://dx.doi.org/10.1016/S0016-5107(04)01878-4

[11] J. Y. Mary, R. Modigliani, “Development and Validation of an Endoscopic Index of the Severity for Crohn's Disease: A Prospective Multicentre Study. Groupe d'Etudes Thérapeutiques des Affections Inflammatoires du Tube Digestif (GETAID)," Gut, Vol. 30, No. 7, 1989, pp. 983-989. http://dx.doi.org/10.1136/gut.30.7.983

[12] D. P. Hurlstone, D. S. Sanders and A. J. Lobo, "Prospective Evaluation of High-Frequency Mini-Probe Ultrasound Colonoscopic Imaging in Ulcerative Colitis: A Valid Tool for Predicting Clinical Severity,” European Journal of Gastroenterology \& Hepatology, Vol. 17, No. 12, 2005, pp. 1325-1331. http://dx.doi.org/10.1097/00042737-200512000-00010

[13] E. G. Seidman, "Role of Endoscopy in Inflammatory Bowel Disease," Gastrointestinal Endoscopy Clinics of North America, Vol. 11, No. 4, 2001, pp. 641-657.

[14] R. B. Canani, L. T. Horatio, G. Terrin, M. T. Romano, E. Miele, A. Staiano, et al., "Combined Use of Noninvasive Tests Is Useful in the Initial Diagnostic Approach to a Child with Suspected Inflammatory Bowel Disease," Journal of Pediatric Gastroenterology and Nutrition, Vol. 42, No. 1, 2006, pp. 9-15. http://dx.doi.org/10.1097/01.mpg.0000187818.76954.9a

[15] L. Ruess, A. R. Blask, D. I. Bulas, P. Mohan, A. Bader, J. S. Latimer, et al., "Inflammatory Bowel Disease in Children and Young Adults: Correlation of Sonographic and Clinical Parameters during Treatment,” American Journal of Roentgenology, Vol. 175, No. 1, 2000, pp. 79-84. http://dx.doi.org/10.2214/ajr.175.1.1750079

[16] R. G. Nielsen, C. Bindslev-Jensen, M. Kruse-Andersen and S. Husby, "Severe Gastroesophageal Reflux Disease and Cow Milk Hypersensitivity in Infants and Children: Disease Association and Evaluation of a New Challenge 
Procedure,” Journal of Pediatric Gastroenterology and Nutrition, Vol. 39, No. 4, 2004, pp. 383-391.

[17] O. H. Gilja, J. G. Hatlebakk, S. Odegaard, A. Berstad, I. Viola, C. Giertsen, et al., "Advanced Imaging and Visualization in Gastrointestinal Disorders," World Journal of Gastroenterology, Vol. 13, No. 9, 2007, pp. 1408-1421.

[18] Y. Patenaude, C. Bernard, R. Schreiber and A. B. Sinsky, "Cow's-Milk-Induced Allergic Colitis in an Exclusively Breast-Fed Infant: Diagnosed with Ultrasound,” Pediatric Radiology, Vol. 30, No. 6, 2000, pp. 379-382. http://dx.doi.org/10.1007/s002470050765

[19] D. Strobel, R. S. Goertz and T. Bernatik, "Diagnostics in Inflammatory Bowel Disease: Ultrasound,” World Journal of Gastroenterology, Vol. 17, No. 27, 2011, pp. 31923197.

[20] M. J. Siegel, C. Carel and S. Surratt, "Ultrasonography of Acute Abdominal Pain in Children,” JAMA, Vol. 266, No. 14, 1991, pp. 1987-1989. http://dx.doi.org/10.1001/jama.1991.03470140099032

[21] P. Skaane, P. F. Amland, T. Nordshus and K. Solheim, "Ultrasonography in Patients with Suspected Acute Appendicitis: A Prospective Study,” British Journal of Radiology, Vol. 63, No. 754, 1990, pp. 787-793. http://dx.doi.org/10.1259/0007-1285-63-754-787

[22] G. Arslan, S. Odegaard, S. Elsayed, E. Florvaag and A. Berstad, "Food Allergy and Intolerance: Response to Intestinal Provocation Monitored by Endosonography," European Journal of Ultrasound, Vol. 15, No. 1-2, 2002, pp. 29-36. http://dx.doi.org/10.1016/S0929-8266(02)00004-6

[23] J. H. Miller and C. R. Kemberling, "Ultrasound Scanning of the Gastrointestinal Tract in Children: Subject Review,” Radiology, Vol., No., 1984, pp. 671-677.

[24] R. Faingold, A. Daneman, G. Tomlinson, P. S. Babyn, D. E. Manson, A. Mohanta, et al., "Necrotizing Enterocolitis: Assessment of Bowel Viability with Color Doppler US," Radiology, Vol. 235, No. 2, 2005, pp. 587-594. http://dx.doi.org/10.1148/radiol.2352031718

[25] J. F. Eidt, T. Harward, J. M. Cook, M. B. Kahn and R. Troillett, "Current Status of Duplex Doppler Ultrasound in the Examination of the Abdominal Vasculature," The American Journal of Surgery, Vol. 160, No. 6, 1990, pp. 604-609.

[26] F. VanBel, P. H. VanZwieten, G. L. Guit and J. Schipper, "Superior Mesenteric Artery Blood Flow Velocity and Estimated Volume Flow: Duplex Doppler US Study of Preterm and Term Neonates,” Radiology, Vol. 174, No. 1, 1990, pp. 165-169.

[27] O. H. Gilja, J. G. Hatlebakk, S. Odegaard, A. Berstad, I. Viola, C. Giertsen, et al., "Advanced Imaging and Visualization in Gastrointestinal Disorders," World Journal of Gastroenterology, Vol. 13, No. 9, 2007, pp. 1408-1421.

[28] B. Limberg, "Diagnosis of Acute Ulcerative Colitis and Crohn's Disease by Colonic Sonography,” Journal of Clinical Ultrasound, Vol. 17, No. 1, 1989, pp. 25-31. http://dx.doi.org/10.1002/jcu.1870170106

[29] S. P. Quillin and M. J. Siegel, "Gastrointestinal Inflammation in Children: Color Doppler Ultrasonography,”
Journal of Ultrasound in Medicine, Vol. 13, No. 10, 1994, pp. 751-756.

[30] . P. Quillin and M. J. Siegel, "Color Doppler US of Children with Acute Lower Abdominal Pain,” Radiographics, Vol. 13, No. 6, 1993, pp. 1281-1293. http://dx.doi.org/10.1148/radiographics.13.6.8290724

[31] D. P. Hurlstone, D. S. Sanders, A. J. Lobo, M. E. McAlindon and S. S. Cross, "Prospective Evaluation of High-Frequency Mini-Probe Ultrasound Colonoscopic Imaging in Ulcerative Colitis: A Valid Tool for Predicting Clinical Severity,” European Journal of Gastroenterology \& Hepatology, Vol. 17, No. 12, 2005, pp. 13251331.

http://dx.doi.org/10.1097/00042737-200512000-00010

[32] C. Faure, N. Belarbi, J. F. Mougenot, M. Besnard, J. P. Hugot, J. P. Cézard, et al., "Ultrasonographic Assessment of Inflammatory Bowel Disease in Children: Comparison with Ileo-Colonoscopy,” Journal of Pediatrics, Vol. 130, No. 1, 1997, pp. 147-151. http://dx.doi.org/10.1016/S0022-3476(97)70325-1

[33] D. Gaitini, A. J. Kreitenberg, D. Fischer, I. Maza and Y. Chowers, "Color-Coded Duplex Sonography Compared to Multidetector Computed Tomography for the Diagnosis of Crohn Disease Relapse and Complications," Journal of Ultrasound in Medicine, Vol. 30, No. 12, 2011, pp. 1691-1699.

[34] M. P. Hiorns, "Imaging of Inflammatory Bowel Disease. How?” Pediatric Radiology, Vol. 38, No. 3, 2008, pp. S512-S517. http://dx.doi.org/10.1007/s00247-008-0835-8

[35] M. J. Siegel, J. A. Friedland and C. F. Hildebolt, "Bowel Wall Thickening in Children: Differentiation with US," Radiology, Vol. 203, No. 3, 1997, pp. 631-635.

[36] S. A. Teefey, M. C. Roarke, J. A. Brink, W. D. Middleton, D. M. Balfe, E. P. Thyssen, et al., "Bowel Wall Thickening: Differentiation of Inflammation from Ischemia with Color Doppler and Duplex US,” Radiology, Vol. 198, No. 2, 1996, pp. 547-551.

[37] H. P. Haber, A. Busch, R. Ziebach and M. Stern, "Bowel Wall Thickness Measured by Ultrasound as a Marker of Crohn's Disease Activity in Children,” Lancet, Vol. 355, No. 9211, 2000, pp. 1239-1240. http://dx.doi.org/10.1016/S0140-6736(00)02092-4

[38] C. Baud, M. Saguintaah, C. Veyrac, A. Couture, J. L. Ferran, G. Barnéon, et al., "Sonographic Diagnosis of Colitis in Children,” European Radiology, Vol. 14, No. 11, 2004, pp. 2105-2119. http://dx.doi.org/10.1007/s00330-004-2358-5

[39] G. Maconi, E. Radice, S. Greco and G. Bianchi Porro, "Bowel Ultrasound in Crohn's Disease," Best Practice \& Research Clinical Gastroenterology, Vol. 20, No. 1, 2006, pp. 93-112. http://dx.doi.org/10.1016/j.bpg.2005.09.001

[40] J. Spalinger, H. Patriquin, M. Miron, G. Marx, D. Herzog, J. Dubois, M. Dubinsky and E. G. Seidman, “Doppler US in Patients with Crohn Disease: Vessel Density in the Diseased Bowel Reflects Disease Activity,” Radiology, Vol. 217, No. 3, 2000, pp. 787-791. http://dx.doi.org/10.1148/radiology.217.3.r00dc19787 
[41] B. Vucelic, "Inflammatory Bowel Diseases: Controversies in the Use of Diagnostic Procedures," Digestive Diseases and Sciences, Vol. 27, No. 3, 2009, pp. 269-277.

[42] K. Horsthuis, S. Bipat, R. J. Bennink and J. Stoker, "Inflammatory Bowel Disease Diagnosed with US, MR, Scintigraphy, and CT: Meta-Analysis of Prospective Studies,” Radiology, Vol. 247, No. 1, 2008, pp. 64-79. http://dx.doi.org/10.1148/radiol.2471070611

[43] A. G. Schreyer, C. Menzel, C. Friedrich, F. Poschenrieder,
L. Egger, C. Dornia, et al., "Comparison of High-Resolution Ultrasound and MRenterography in Patients with Inflammatory Bowel Disease,” World Journal of Gastroenterology, Vol. 17, No. 8, 2011, pp. 1018-1025.

[44] M. Alison, A. Kheniche, R. Azoulay, S. Roche, G. Sebag and N. Belarbi, "Ultrasonography of Crohn Disease in Children,” Pediatric Radiology, Vol. 37, No.1 1, 2007, pp. 1071-1082. http://dx.doi.org/10.1007/s00247-007-0559-1 